\title{
Long-term risk of IDDM in first-degree relatives of patients with IDDM
}

\author{
T. Lorenzen ${ }^{1}$, F. Pociot ${ }^{1}$, P.Hougaard ${ }^{2}$, J.Nerup ${ }^{1}$ \\ ${ }^{1}$ Steno Diabetes Center, Gentofte, Denmark \\ ${ }^{2}$ Biostatistical Department, Novo-Nordisk A/S, Bagsværd, Denmark
}

Summary Due to a short observation period previous studies may have underestimated prevalence and recurrence risk of IDDM in relatives of IDDM patients. To obtain a more exact life-time risk estimate we identified 310 probands, representative of Danish IDDM patients, characterized by current age more than 50 years, age at onset 40 years or less and diabetes duration of more than 30 years. Family data were obtained from 291 probands. Mean "observation" times (age) $( \pm$ SD) for siblings $(n=553)$ and offspring $(n=359)$ were $59.4 \pm 16.1$ years and $33.8 \pm 8.8$ years, respectively. Of the probands $73(25.1 \%)$ had at least one first-degree relative with IDDM. Seventeen percent had at least one affected sibling. An increase from $10.4 \%$ to $22.4 \%$ of having first-degree relatives with IDDM among probands with age at onset below 20 years was observed during the period from proband at age 21 years up to 1 September 1992. Among affected siblings $48 \%$ of the second cases were affected more than 10 years after the first affected sibling. Using the life-table method cumulative recurrence risks from time of birth were calculated for siblings up to age 30 years of $6.4 \%$ and up to age 60 years of $9.6 \%$. For offspring the risk up to age 34 years was $6.3 \%$. In addition, we present a life-table method evaluating the $\mathrm{cu}$ mulative recurrence risk from time of onset in the proband, as this is the most relevant when giving genetic counselling. In conclusion, the long-term risks of IDDM in siblings and offspring are high compared to that shown in previous reports. [Diabetologia (1994) 37: 321-327]

Key words IDDM, first-degree relatives, familial aggregation, recurrence risk, life-table analysis.
The aetiology of IDDM is still rather poorly understood. The major genetic predisposition is conferred by HLA-class II genes [1-3] but genes outside this region may also confer susceptibility [4-8]. Furthermore, environmental factors are thought to be important for the initiation of the disease [9-11]. Epidemiological studies may be helpful in increasing our understanding of IDDM and are essential for generation of preventive and interventive strategies aimed at the eradication of the disease. When studying familial aggregation of

Received: 14 July 1993

and in revised form: 13 October 1993

Corresponding author: Dr. J.Nerup, Steno Diabetes Center, Niels Steensens Vej 2, DK-2820 Gentofte, Denmark

Abbreviations: IDDM, insulin-dependent diabetes mellitus; SE, standard error.
IDDM the composition and representativeness of the study population are obviously important for allowing direct comparisons between results from different regions and centres.

Several studies have reported the prevalence of IDDM patients having affected first-degree relatives within a range of 5 to $19 \%$ [13-24]. However, many of these studies are not directly comparable, primarily due to methodological differences. Often, the study populations comprised only children or adolescent probands $[13,15,18,19,21,24]$, were designed as incidence studies $[15,16,18]$, had short follow-up periods and/or only two generations were studied. In addition, marked differences in incidence rates of IDDM between racial groups and countries have been reported [15, 25-28] and may be partly responsible for the variation in the results.

For members of affected families an estimate of risk of IDDM is an important issue. Published estimates of 
Table 1. Characterization of probands and relatives

\begin{tabular}{llll}
\hline & Total & Familial & Sporadic \\
\hline Probands & & & \\
$n$ & 291 & 73 & 218 \\
Sex (male:female) & $155: 136$ & $40: 33$ & $115: 103$ \\
Age (years) & $63(51-85)$ & $64(51-85)$ & $63(51-85)$ \\
Age at onset (years) & $22(1-40)$ & $23(1-37)$ & $21(2-40)$ \\
Duration of IDDM (years) & $40(30-70)$ & $42(31-70)$ & $40(30-69)$ \\
Relatives & & & \\
Mean "observation" time (years) & & & \\
$\quad$ per sibling & $59.4 \pm 16.1$ & $57.4 \pm 17.3$ & $60.5 \pm 15.3$ \\
per offspring & $33.8 \pm 8.8$ & $34.1 \pm 9.4$ & $33.7 \pm 8.5$ \\
\hline
\end{tabular}

All $p_{\mathrm{c}}$-values $>0.3$ for comparisons between familial and sporadic groups

risks for siblings to probands with IDDM vary considerably. In a previous Danish study [29], risks for siblings of $6.9 \%$ up to age 40 years and of $15.9 \%$ up to age 70 years were reported. However, this study gave no information on insulin treatment for the affected relatives. Other studies on Caucasoid populations observed risks of $5.6 \%$ up to age 16 years [ 30$], 5.5 \%$ up to age 40 years [14], $6.6 \%$ up to age 80 years [31], $7.6 \%$ up to age 25 years [32], $4.4 \%$ up to age 30 years [13], $6.3 \%$ up to age 30 years [33] and $12.5 \%$ up to age 30 years [19]. To our knowledge only two studies have estimated recurrence risks to offspring of probands with IDDM. Using the life-table method, Degnbøl and Green [29] calculated risks of $2.8 \%$ up to age 20 years and of $5.4 \%$ up to age 35 years while Tillil and Köbberling [31] estimated a recurrence risk of $4.9 \%$ up to age 80 years.

The aim of the present study was to assess the presence of IDDM among first-degree relatives of patients with long-term IDDM and to assess epidemiological characteristics of the included patients and their first-degree relatives.

\section{Subjects and methods}

All patients with IDDM alive on 1 September 1992, characterized by current age more than 50 years, age at onset 40 years or less and diabetes duration of more than 30 years attending the Steno Diabetes Center were identified for the present study. $\mathrm{Pa}$ tients fulfilling these inclusion criteria were asked to complete a questionnaire requesting the following information: age at onset of IDDM, age and gender of all full-siblings and offspring, and if any of these relatives was deceased, their age at the time of death. We asked whether any of their first-degree relatives had been diagnosed with IDDM and if relevant, the year of onset. Questionnaires returned incomplete were followed-up with interviews.

The diagnosis of IDDM in the probands was established using the following criteria: age at onset 40 years or less, lean body weight and insulin requirement since the time of diagnosis [34].

Diabetic first-degree relatives were included if they also fulfilled the above criteria. In relatives, if the age at onset was more than 40 years, the diagnosis was established based on additional information concerning proneness to ketosis and low body weight at the time of diagnosis.
The study was approved by the Ethics Committee of the County of Copenhagen. Informed consent was obtained from all patients.

\section{Statistical analysis}

Results are expressed as median and range. The Mann-Whitney test was used to compare the medians of two groups for independent continuous variables. For independent categorical variables, the chi-square test was used to compare proportions.

Recurrence risks for siblings and offspring were calculated. Using the life-table method (Nelson) \pm SE, risks were calculated for every age (expressed in years) as number of cases per number of persons at risk. The cumulative risk was calculated by addition of the risk values from age 1 year up to several different ages. The life-table analyses were performed by two different methods: a) recurrence risk was estimated with a fixed starting point at the time of birth in siblings and offspring, respectively, and b) life tables were based only on events and time at risk after onset in the proband. For comparison of incidence rates the logrank test was used.

The level of statistical significance was chosen to be 0.05 (two-tailed). When multiple comparisons were performed between groups, $p$-values were multiplied by the number of comparisons $\left(p_{\mathrm{c}}\right)$.

\section{Results}

The inclusion criteria were fulfilled by 310 patients. Questionnaires were distributed to them and were returned from 296 patients resulting in a participation rate of $95.5 \%$. Five patients were excluded due to incomplete data, which could not be obtained on followup interview. In 10 families it was not possible to establish the exact birth order of individuals with IDDM within the families. However, their questionnaires were complete according to the remaining data and thus, these cases were not excluded. In two sibling pairs both had completed the questionnaire and these families were, therefore, included twice. For the final data analysis 291 patients were included. Seventy-three $(25.1 \%)$ of these had at least one first-degree relative with IDDM and were referred to as familial probands, whereas 218 were sporadic probands (i.e. patients with 
Table 2. Characterization of probands and relatives according to age at onset in probands

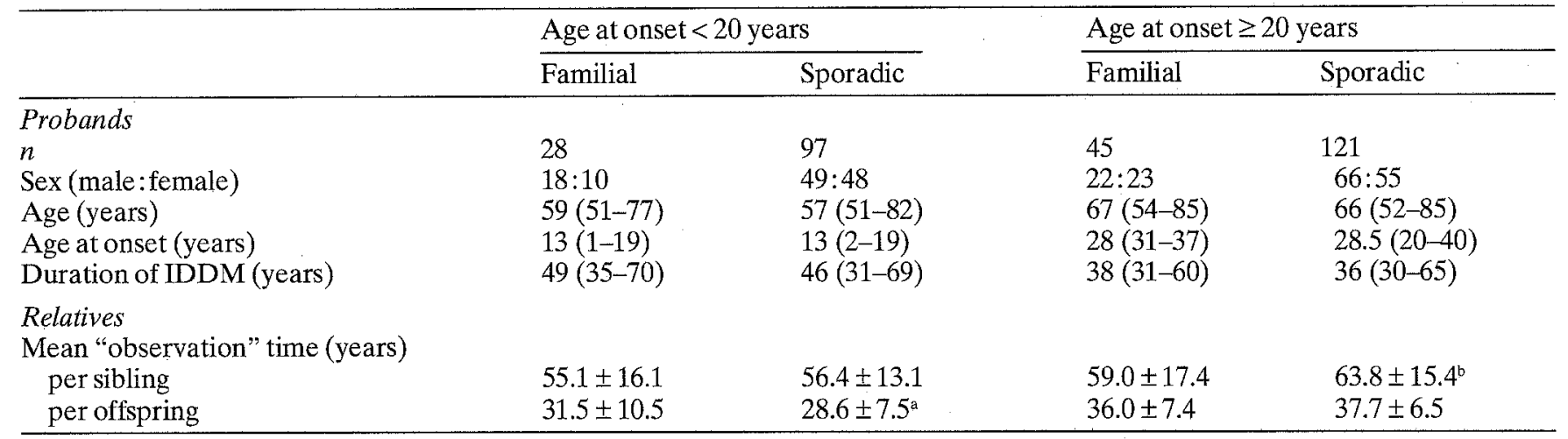

${ }^{\mathrm{a}} p_{\mathrm{c}}=0.06$ and ${ }^{\mathrm{b}} p_{\mathrm{c}}=0.04$ for comparison of familial and sporadic cases. All other $p_{\mathrm{c}}$-values $>0.5$ for comparisons between familial and sporadic groups

Table 3. Comparison of data for probands with age at onset below 20 years with data from a nationwide population-based survey of childhood and adolescence patients

\begin{tabular}{|c|c|c|c|c|}
\hline \multirow[b]{2}{*}{ Prevalence of probands having } & \multicolumn{2}{|c|}{ Present study } & Pociot et al. [24] & \multirow[b]{2}{*}{$\begin{array}{l}\mathrm{B} \text { vs C } \\
p \text {-values }\end{array}$} \\
\hline & $\begin{array}{l}\text { A } \\
\text { At present }\end{array}$ & $\begin{array}{l}\text { B } \\
\text { At age 21 }\end{array}$ & $\begin{array}{l}\mathrm{C} \\
\text { Up to age } 21\end{array}$ & \\
\hline Affected siblings & $15.2 \%$ & $8.0 \%$ & $5.0 \%$ & 0.23 \\
\hline Affected parents & $4.8 \%$ & $4.8 \%$ & $9.0 \%$ & 0.20 \\
\hline Affected offspring & $7.2 \%$ & - & - & - \\
\hline
\end{tabular}

a uncorrected

no affected first-degree relatives). Among sporadic probands $79(37 \%)$ had no siblings and/or no offspring, thus not being fully informative families. They are, however, considered "sporadic" in the present study.

Among all probands the male: female ratio was 1.14 $(155: 136)(p=0.48)$. The median age of the probands was 63 years (51-85), median age at onset was 22 years (1-40), and median duration of IDDM was 40 years (30-70). No differences were observed between familial and sporadic cases (Table 1). Mean "observation" time (age) ( \pm SD) from time of birth until 1 September 1992 or until time of death, was $59.4 \pm 16.1$ years in siblings and $33.8 \pm 8.8$ years in offspring, and significant differences were not observed between the familial and the sporadic groups (Table 1).

None of the affected offspring had been diagnosed at age older than 40 years (range 2-34 years). Of the insulin-treated siblings and parents affected at age more than 40 years, eight siblings (range $45-60$ years) and three parents (range 42-56 years), all from different families, fulfilled our criteria for IDDM in relatives. In four of these families, the proband had at least one more affected first-degree relative with age at onset at 40 years or less. Thus, seven of 73 familial probands $(9.6 \%)$ had a first-degree relative with age at onset after 40 years of age as the only affected relative. The number of probands without offspring was not different between the two groups $(p=0.78)$.
The prevalence of familial IDDM was $25.1 \%$ (73: 291 ). If only affected siblings and offspring to the probands were included the prevalence was $21.6 \%$.

Familial probands were further characterized. Eleven probands $(3.8 \%)$ had a father with IDDM, whereas seven $(2.4 \%)$ had an affected mother $(p=$ 0.47 ). Forty-eight probands $(16.5 \%)$ had at least one sibling with IDDM. Nineteen probands $(6.5 \%)$ had an offspring with IDDM. In nine families, three siblings were affected and in two families, four siblings were affected. In total, 18 probands $(6.2 \%)$ had more than one affected first-degree relative.

In the diabetes concordant siblings we observed significant differences between median age at onset for index cases (first affected sibling in a family) and second cases: 19 years $(1-32)$ vs 28 years $(10-60),(p<$ 0.0001 ). Of second cases in these sibling pairs, $48 \%$ were affected more than 10 years after the index case. Median age at onset for third cases $(n=9)$ was 30 years $(12-55)$ and for fourth cases $(n=2) 43.5$ years $(35$ and 52 years). In 27 of $46(58.6 \%)$ affected sibling pairs (index-case and second case), the proband was identical with the index case.

Probands were grouped according to age at onset in intervals of 1-19 years and 20-40 years, respectively (Table 2). A significant difference in "observation" time for siblings of probands with age at onset of more than 20 years was observed $\left(p_{\mathrm{c}}=0.04\right)$. The longest 
Table 4. Cumulative recurrence risk of IDDM in siblings $(n=553)$ and offspring $(n=359)$ from the time of birth

\begin{tabular}{|c|c|c|}
\hline Age (years) & $\begin{array}{l}\text { Cumulative risk for } \\
\text { siblings \% (SE) }\end{array}$ & $\begin{array}{l}\text { Cumulative risk for } \\
\text { offspring \% (SE) }\end{array}$ \\
\hline 2 & $0.2(0.2)$ & $0.8(0.5)$ \\
\hline 3 & $0.4(0.3)$ & $0.8(0.5)$ \\
\hline 4 & $0.6(0.3)$ & $1.1(0.6)$ \\
\hline 5 & $0.7(0.4)$ & $1.1(0.6)$ \\
\hline 6 & $0.9(0.4)$ & $1.4(0.6)$ \\
\hline 8 & $0.9(0.4)$ & $1.7(0.7)$ \\
\hline 9 & $0.9(0.4)$ & $2.0(0.8)$ \\
\hline 10 & $1.1(0.5)$ & $2.3(0.8)$ \\
\hline 11 & $1.1(0.5)$ & $2.6(0.9)$ \\
\hline 12 & $1.3(0.5)$ & $2.6(0.9)$ \\
\hline 14 & $1.5(0.5)$ & $2.9(0.9)$ \\
\hline 15 & $1.7(0.6)$ & $3.2(1.0)$ \\
\hline 17 & $1.9(0.6)$ & $3.2(1.0)$ \\
\hline 18 & $2.5(0.7)$ & $3.2(1.0)$ \\
\hline 19 & $2.6(0.7)$ & $3.2(1.0)$ \\
\hline 22 & $2.8(0.7)$ & $3.2(1.0)$ \\
\hline 23 & $3.0(0.8)$ & $3.2(1.0)$ \\
\hline 24 & $3.6(0.8)$ & $3.8(1.1)$ \\
\hline 25 & $4.2(0.9)$ & $3.8(1.1)$ \\
\hline 28 & $4.4(0.9)$ & $3.8(1.1)$ \\
\hline 29 & $4.8(1.0)$ & $4.6(1.2)$ \\
\hline 30 & $6.4(1.1)$ & $4.6(1.2)$ \\
\hline 32 & $6.6(1.1)$ & $4.6(1.2)$ \\
\hline 34 & $6.6(1.1)$ & $6.3(1.5)$ \\
\hline 35 & $7.1(1.2)$ & \\
\hline 37 & $7.3(1.2)$ & \\
\hline 38 & $7.5(1.2)$ & \\
\hline 45 & $7.7(1.2)$ & \\
\hline 50 & $8.2(1.3)$ & \\
\hline 51 & $8.4(1.3)$ & \\
\hline 55 & $9.0(1.4)$ & \\
\hline 56 & $9.2(1.4)$ & \\
\hline 60 & $9.6(1.4)$ & \\
\hline
\end{tabular}

All values are given with an accuracy of 1 year. Only age groups where cases were reported are shown

"observation" time was found for siblings to sporadic cases. No other statistically significant differences in epidemiological characteristics between familial and sporadic cases were found (Table 2). The prevalences of affected first-degree relatives in the two groups were similar $(22.4 \%$ and $28.8 \% ; p=0.42)$ and we found no difference in prevalence of IDDM for parents, siblings and offspring (data not shown) between familial and sporadic cases. No statistically significant differences in risks to first-degree relatives of probands with age at onset before and after 20 years of age were observed (data not shown).

Data for probands with age at onset below 20 years were compared to data from a recent nationwide survey of Danish childhood and adolescence patients [24] (Table 3 ). In that study according to the inclusion criteria the probands were aged $0-20$ years. At age 21 years of the probands from the present study, the prevalence of probands having first-degree relatives with IDDM was $10.4 \%$, not statistically different from that of $12.8 \%$ in the recent study of young probands [24], $(p=0.54)$.
Table 5. Cumulative recurrence risk of IDDM in siblings $(n=506)$ and offspring $(n=355)$ from time of diagnosis in the proband

\begin{tabular}{rll}
\hline Age (years) & $\begin{array}{l}\text { Cumulative risk for } \\
\text { siblings \% (SE) }\end{array}$ & $\begin{array}{l}\text { Cumulative risk for } \\
\text { offspring \% (SE) }\end{array}$ \\
\hline 2 & $0.0(0.0)$ & $0.7(0.5)$ \\
5 & $2.0(2.1)$ & $0.7(0.5)$ \\
6 & $2.0(2.1)$ & $1.0(0.6)$ \\
8 & $2.0(2.1)$ & $1.3(0.7)$ \\
9 & $2.0(2.1)$ & $1.7(0.7)$ \\
10 & $3.1(2.3)$ & $2.0(0.8)$ \\
11 & $3.1(2.3)$ & $2.3(0.9)$ \\
14 & $3.9(2.4)$ & $2.6(0.9)$ \\
15 & $3.9(2.4)$ & $2.9(1.0)$ \\
17 & $4.4(2.5)$ & $2.9(1.0)$ \\
18 & $5.5(2.6)$ & $2.9(1.0)$ \\
22 & $6.0(2.7)$ & $2.9(1.0)$ \\
24 & $6.8(2.7)$ & $3.5(1.1)$ \\
25 & $7.1(2.7)$ & $3.5(1.1)$ \\
28 & $7.4(2.8)$ & $3.5(1.1)$ \\
29 & $8.1(2.8)$ & $4.3(1.1)$ \\
30 & $9.3(2.9)$ & $4.3(1.1)$ \\
32 & $9.6(2.9)$ & $4.3(1.1)$ \\
34 & $9.6(2.9)$ & $6.0(1.5)$ \\
35 & $10.1(2.9)$ & \\
38 & $10.4(2.9)$ & \\
45 & $10.6(2.9)$ & \\
50 & $11.1(2.9)$ & \\
51 & $11.3(3.0)$ & \\
55 & $11.9(3.0)$ & \\
56 & $12.2(3.0)$ & \\
60 & $12.5(3.0)$ & \\
\hline & &
\end{tabular}

All values are given with an accuracy of 1 year. Only age groups where cases were reported are shown. Example of calculating risk from time of onset in the proband: if a sibling to a newly diagnosed patient is 10 years old, his risk of developing IDDM up to age 45 years is calculated by subtraction of the cumulative risk estimate at age 9 years from the value at age 45 years. Result: $10.6 \%-2.0 \%=8.6 \%$. The incidence can be transformed to a probability using the formula 1 - exp ${ }^{\text {-incidence }}$, which in this example results in a value of $8.2 \%$

Recurrence risk of IDDM in the family was estimated by use of life tables. The families in which it was not possible to establish the exact birth order of all siblings and offspring were not included. The total sample included 553 siblings (46 with IDDM) and 359 offspring (18 with IDDM). In the life tables which were designed to estimate cumulative recurrence risks from time of onset in the proband, 47 siblings and 4 offspring were excluded because they were deceased and/or diagnosed before onset of IDDM in the proband. Thus, in these risk calculations were included 506 siblings and 355 offspring of whom 29 and 16, respectively, were affected during the observation period. In siblings the cumulative recurrence risk from time of birth up to age 30 years was $6.4 \pm 1.1 \%$ and up to age 60 years, $9.6 \pm 1.4 \%$. For offspring the cumulative recurrence risk was $6.3 \pm 1.5 \%$ up to age 34 (Table 4). Estimated from time of onset in the proband the cumulative recurrence risk in siblings was 
$12.5 \pm 3.0 \%$ up to age 60 years in siblings and in offspring the recurrence risk up to age 34 years was $6.0 \pm 1.5 \%$ (Table 5).

\section{Discussion}

We have collected information on familial data from 291 patients with IDDM characterized by current age more than 50 years, age at onset 40 years or less and diabetes duration of more than 30 years. Previous studies have shown [35] that this population can be regarded as representative of Danish IDDM patients.

Mean "observation" times ( \pm SD) in siblings and offspring were $59.4 \pm 16.1$ years and $33.8 \pm 8.8$ years, respectively, thereby providing opportunity to determine the long-term risk of IDDM in siblings and offspring.

The diagnosis of IDDM was established on the criteria of age at onset at 40 years or less, insulin requirement since the time of diagnosis and clinical evaluation. This definition is based on a prospective study performed by Agner et al. [34] at the Steno Diabetes Center. They found that patients diagnosed before the age of 40 years and clinically evaluated as IDDM patients had fasting C-peptide levels indicating insulin-dependency 18 months after diagnosis. First-degree relatives with age at onset of more than 40 years were included only if they had required insulin since the time of diagnosis in addition to proneness to ketosis and low body weight at the time of diagnosis.

We found that the probands in the present study were older at the time of diagnosis (22 years) compared to other studies $[12,13,15,19,21,23,24,30,33]$. One obvious reason might be the inclusion criteria. Age at onset was defined as a range of $0-40$ years in contrast to most other studies, in which the upper limit is lower. However, in a subpopulation comprising probands with age at onset below 20 years, the median age at onset (13 years) was higher compared to that found in a recent Danish study [24] of young probands with age at onset less than 20 years (median 9 years, range $0-19$ years). Low age at onset is associated with development of nephropathy, cardiovascular diseases and increased mortality [35]. Thus, another possible explanation for the observed higher age at onset in the present study is, that more patients with low age at onset were deceased by 1 September 1992 due to complications.

The prevalence of probands with at least one firstdegree relative affected with IDDM was $25.1 \%$. This value is higher than reported in previous studies. We found the prevalence of probands having affected parents to be low compared to most other studies [18, 23, 24] probably due to the fact that the probands were born in the early part of this century during which the likelihood of diabetic patients having children, especially women, was small. If the parent generation was excluded the prevalence of probands with affected first-degree relatives was $21.6 \%$. This was primarily due to a high number of probands with affected siblings $(16.5 \%)$ compared to other studies $[12-14,18,24]$. Actuarial analysis of the present material demonstrated that this was due to a significant risk for developing IDDM late in life. In sibling pairs concordant for IDDM we found in agreement with previous reports $[13,21,24,36]$ that age at onset in index cases was significantly lower than in second cases. In $48 \%$ of the sibling pairs concordant for IDDM the second case was diagnosed more than 10 years after the index case. This observation is in contrast to data from Olmos et al. [37] in which 49 non-diabetic identical twins of recently diagnosed IDDM patients were followed for 2 to 24 years (median 9 years). Their data indicated that by 12 years of follow-up, $34 \%$ of identical twins would have developed IDDM and thereafter only $2 \%$ would do so [37]. Interestingly, we observed a trend for increased risk to siblings of probands with age at onset more than 20 years, while the opposite was observed for offspring. The observation that low age at onset is associated with a stronger genetic impact, e.g. as supported by evidence for stronger HLA-association with younger age at onset was not tested in the present study since no typing data were accessible.

To compare the present data with data from a recent nationwide study of Danish childhood and adolescence patients [24], probands with age at onset below 20 years were identified. Of special interest was the increment from $10.4 \%$ to $22.4 \%$ in probands having affected firstdegree relatives diagnosed during the period after the probands reached the age of 21 years. These data strongly suggest that a marked risk of second cases exists many years after the first case which is also documented by the life-table analysis.

One of the life-table analyses was designed to allow estimation of cumulative recurrence risk from time of diagnosis in the proband. In most, if not all, previous studies recurrence risk was estimated from time of birth. The other approach, however, from a clinical point of view seems more relevant, e.g. when giving genetic counselling to family members to a newly-diagnosed patient, though it means that a number of individuals were excluded from the analysis.

As a consequence of the study design only families with at least one affected member were included in the analyses. The families were identified through the proband, who was not included in the estimation of recurrence risk. It could be suggested that familial cases are more likely to be referred to the Steno Diabetes Center. However, patients at Steno Diabetes Center come from a certain geographic area (the County of Copenhagen); approximately $90 \%$ of all IDDM patients from this defined area are referred to the center. Thus, a referral bias is not likely to occur, at least not of a magnitude which would influence the estimations of the present study. The long duration of IDDM may influence the interpretation of the results, since it is well 
known, that the mortality is increased among patients with young age at onset and diabetic nephropathy. In a recent study [38] on patients fulfilling inclusion criteria identical to those of the present study except for diabetes duration of at least 10 years and clinical nephropathy, the prevalence of patients having siblings with IDDM was not different from the corresponding prevalence in the normoalbuminuric control group. Hence, these data do not support that patients with severe late complications and early death have fewer first-degree relatives with IDDM. Since low age at onset may be associated with a stronger genetic impact [39], it could be hypothesized that patients with young age at onset and early death may have more affected relatives. Thus, the presence of IDDM among first-degree relatives of patients with long-term IDDM may be even higher than we have reported.

We found the recurrence risk of IDDM in the families of the study population to be higher than hitherto reported from most studies [13, 14, 31-33] but comparable to the high value of a recent report from Allen et al. [19]. The cumulative recurrence risk of siblings at age 60 years was estimated to $9.6 \%$ and interestingly, we also found that the recurrence risk in siblings was significant even after age 30 years $(3.2 \%$ from 30 to 60 years). However, in order to confirm these findings, future prospective long-term studies dealing with familial prevalence and recurrence risk of IDDM are needed.

Acknowledgements. The excellent secretarial assistance of Ms. E. Marquardsen is greatly appreciated. This study was in part supported by the Danish Diabetes Association.

\section{References}

1. Nerup J, Mandrup-Poulsen T, Mølvig J (1987) The HLAIDDM association: implications for etiology and pathogenesis of IDDM. Diabetes Metab Rev 3: 779-802

2. Svejgaard A, Ryder L.P (1989) HLA and insulin dependent diabetes: An overview. Genet Epidemiol 6:1-14

3. Todd JA (1990) Genetic control of autoimmunity in IDDM. Immunol Today 11: 122-129

4. Julier C, Hyer RN, Davies J et al. (1991) Insulin-IGF2 region on chromosome $11 \mathrm{p}$ encodes a gene implicated in HLADR4-dependent diabetes susceptibility. Nature 354: 155-159

5. Bain SC, Prins JB, Hearne CM et al. (1992) Insulin gene region encoded susceptibility to type 1 diabetes is not restricted to HLA-DR4-positive individuals. Nature Genetics 2: 212-215

6. Pociot F, Mølvig J, Wogensen L, Worsaa H, Nerup J (1992) A TaqI polymorphism in the human interleukin $1 \beta$ gene correlates with IL-1 $\beta$ secretion in vitro. Eur J Clin Invest 22: 396-402

7. Lorenzen T, Pociot F, Nerup J (1992) Manganese superoxide dismutase (MnSOD) gene polymorphisms in IDDM patients and controls. Diabetologia 35: [Suppl 1]: A71 (Abstract)

8. Pociot F, Briant L, Jongeneel CV et al. (1993) Association of tumor necrosis factor (TNF) and class II major histocompatibility complex alleles with the secretion of TNF- $\alpha$ and TNF- $\beta$ by human mononuclear cells: a possible link to insulin-dependent diabetes mellitus. Eur J Immunol 23: 224-231

9. Yoon JW (1992) Induction and prevention of IDDM mellitus by viruses. Diabete Metab 18: 378-386

10. Karjalainen J, Martin JM, Knip M et al. (1992) A bovine albumin peptide as a possible trigger of insulin dependent diabetes mellitus. N Eng1 J Med 327: 302-307

11. Kostraba JN, Gay EC, Rewers M, Hamman RF (1992) Nitrate levels in community drinking water and risks of IDDM. Diabetes Care 15: 1505-1508

12. Jaworski MA, Colle E, Guttmann RD et al. (1980) Insulin dependent diabetes: a comparison of families with single and multiple affected siblings. Diabetologia 19:97-100

13. Wagener DK, Sacks JM, LaPorte R, MacGregor IM (1982) The Pittsburg Study of insulin-dependent diabetes mellitus. Risk for diabetes among relatives of IDDM. Diabetes 31: 136-144

14. Chern MM, Anderson VE, Barbosa J (1982) Empirical risk for insulin-dependent diabetes (IDD) in sibs. Further definition of genetic heterogeneity. Diabetes 31: 1115-1118

15. Lorenzi M, Cagliero E, Schmidt NJ (1985) Racial differences in incidence of juvenile-onset type 1 diabetes: epidemiologic studies in southern California. Diabetologia 28: 734-738

16. Mason DR, Scott RS, Darlow BA (1986) Epidemiology of insulin-dependent diabetes mellitus in Canterbury, New Zealand. Diabetes Res Clin Pract 3: 21-29

17. Karjalainen J, Salmela P, Ilonen J et al. (1989) A comparison of childhood and adult IDDM mellitus. N Engl J Med 320: $881-885$

18. Dahlquist G, Blom L, Tuvemo T, Nyström L, Sandström A, Wall S (1989) The Swedish childhood diabetes study - results from a nine year case register and a one year case-referent study indicating that type 1 (insulin-dependent) diabetes mellitus is associated with both type 2 (non-insulin-dependent) diabetes mellitus and autoimmune disorders. Diabetologia $32: 2-6$

19. Allen C, Palta M, Dálessio DJ (1991) Risk of diabetes in siblings and other relatives of IDDM subjects. Diabetes 40: $831-836$

20. Cheta D, Dumitrescu C, Georgescu M et al. (1990) A study on the types of diabetes mellitus in first degree relatives of diabetes patients. Diabete Metab 16: 11-15

21. O'Leary LA, Dorman JS, LaPorte R et al. (1991) Familial and sporadic insulin-dependent diabetes: evidence for heterogenious etiologies? Diabetes Res Clin Pract 14: 183-190

22. Ramachandran A, Snehalatha C, Premila L, Mohan V, Viswanathan M (1990) Familial aggregation in type 1 (insulin-dependent) diabetes mellitus: A study from South India. Diabetic Med 7: 876-879

23. Tuomilehto J, Lounamaa R, Tuomilehto-Wolf E et al. (1992) Epidemiology of childhood diabetes mellitus in Finland background of a nationwide study of type 1 (insulin-dependent) diabetes mellitus. Diabetologia 35: 70-76

24. Pociot F, Nørgård K, Hobolth N, Andersen O, Nerup J and the Danish study group of diabetes in childhood (1993) A nationwide population-based study of the familial aggregation of insulin-dependent diabetes in Denmark. Diabetologia 36: $870-875$

25. LaPorte RE, Tajima N, Åkerblom HK et al. (1985) Geografic differences in the risk of insulin-dependent diabetes mellitus: the importance of registries. Diabetes Care 8: 101-107

26. Gay E, Hamman RF, Carosone-Link PJ et al. (1989) Colorado IDDM Registry: lower incidence of IDDM in Hispanics. Comparison of disease characteristics and care patterns in biethnic population. Diabetes Care 12: 701-708 
27. The WHO Multinational Project for Childhood Diabetes Group (1991) Familial insulin-dependent diabetes mellitus (IDDM) epidemiology: standardization of data for the DIAMOND Project. Bull WHO 69: 767-777

28. Green A, Gale EAM, Patterson CC, the EURODIAB ACE Study Group (1992) Incidence of childhood-onset insulindependent diabetes mellitus: the EURODIAB ACE study. Lancet 339: 905-909

29. Degnbøl B, Green A (1978) Diabetes mellitus among first and second-degree relatives of early onset diabetics. Ann Hum Genet 42: 25-47

30. Gamble DR (1980) An epidemiological study of childhood diabetes affecting two or more siblings. Diabetologia 19: 341-344

31. Tillil H, Köbberling J (1982) Age-corrected empirical genetic risk estimates for first degree relatives of IDDM patients. Diabetes 36: 93-99

32. Tarn AC, Dean BM, Schwarz G et al. (1988) Predicting insulin-dependent diabetes. Lancet I: $845-850$

33. Gavard A, Dorman JS, LaPorte RE et al. (1992) Sex differences in secondary attack rate of IDDM to siblings of probands through older ages. Diabetes Care 15: 559-561
34. Agner T, Damm P, Binder C (1987) Remission in IDDM mellitus: prospective study of basal C-peptide and insulin dose in 268 consecutive patients. Diabetes Care 10: 164-169

35. Borch-Johnsen K (1989) The prognosis of insulin-dependent diabetes mellitus. An epidemiological approach. Dan Med Bull 36: 336-349

36. Dechamps I, Lestradet H, Busson M, Hors J (1984) Evaluation of recurrence risk in siblings of diabetic children: importance of age and birth order in relation to HLA genotypes. Diabetes Res 1: 125-130

37. Olmos P, A'Hern R, Heaton DA et al. (1988) The significance of the concordance rate for type 1 (insulin-dependent) diabetes in identical twins. Diabetologia 31:747-750

38. Borch-Johnsen K, Nørgård K, Hommel E et al. (1992) Is diabetic nephropathy an inherited complication? Kidney Int 41: 719-722

39. Svejgaard A, Jakobsen K, Platz P et al. (1986) HLA associations in insulin-dependent diabetes: search for heterogeneity in different groups of patients from a homogeneous population. Tissue Antigens 28: 237-244 